\title{
CXVIII. STUDIES IN THE BIOCHEMISTRY OF MICRO-ORGANISMS.
}

\author{
XLIX. PALITANTIN, $\mathrm{C}_{14} \mathrm{H}_{22} \mathrm{O}_{4}$, A HITHERTO \\ UNDESCRIBED METABOLIC PRODUCT OF \\ PENICILLIUM PALITANS WESTLING.
}

\author{
BY JOHN HOWARD BIRKINSHAW AND HAROLD RAISTRICK. \\ From the Division of Biochemistry, London School of Hygiene and \\ Tropical Medicine, University of London.
}

(Received March 28th, 1936.)

\begin{abstract}
ALSBERG AND BLACK [1913] described a new mould metabolic product, penicillic acid, $\mathrm{C}_{8} \mathrm{H}_{10} \mathrm{O}_{4}$, which they isolated from cultures of Penicillium puberulum Bainier. Birkinshaw et al. [1936] have recently reported that cultures of Alsberg and Black's strain of $P$. puberulum which, in their hands, gave moderate yields of penicillic acid some seven years ago, no longer produced any penicillic acid in 1933. Search was therefore made for other strains of $P$. puberulum. It was found that Morgan [1933] and Moir [1933] had recorded that this species of fungus is frequently met with in certain discolorations of New Zealand cheese. Through the good offices of the High Commissioner for New Zealand we were able to obtain three different strains of the organism, isolated by Messrs G. F. V. Morgan and J. O. C. Neill from New Zealand Cheddar cheese, and believed by them to be strains of $P$. puberulum.

We found however that when these three strains were grown on Raulin-Thom glucose medium no penicillic acid was formed, but considerable quantities of a hitherto undescribed mould metabolic product were isolated. The question then arose as to the identity or otherwise with $P$. puberulum of the New Zealand cultures. They were therefore submitted to Dr Charles Thom of the United States Bureau of Agriculture. He reported that they were not identical with $P$. puberulum, but were more closely allied to the $P$. terrestre Jensen series, or to $P$. solitum Westling or to $P$. palitans Westling - three species which are difficult to distinguish from each other on purely morphological grounds. Cultures of each of these three organisms, together with the three New Zealand strains and Alsberg and Black's strain of $P$. puberulum were therefore grown under parallel conditions on Raulin-Thom glucose medium. The new metabolic product, for which the name palitantin is suggested, was isolated from cultures of the type strain of $P$. palitans [Westling, 1911] distributed by the Centraalbureau voor Schimmelcultures, Baarn, and from each of the three New Zealand strains (none of these four organisms produced any penicillic acid); a different and hitherto undescribed metabolic product, which will form the subject of a future communication, was isolated from $P$. terrestre; no palitantin was produced by $P$. puberulum and nothing of interest could be isolated from $P$. solitum. We are therefore of the opinion that the cultures isolated by Morgan and Neill from New Zealand cheese are more accurately named as strains of $P$. palitans with which they agree closely in morphological characteristics. This opinion is shared by Dr Thom.
\end{abstract}


Palitantin is a colourless crystalline substance and has the empirical formula $\mathrm{C}_{14} \mathrm{H}_{22} \mathrm{O}_{4}$. Its molecular constitution has not yet been fully elucidated, but the following points bearing on this question have been established:

1. It is optically inactive, is a neutral substance, and its molecule contains three active hydrogen atoms.

2. It contains an aldehyde group, since it gives a positive Schiff's reaction, and the usual aldehyde derivatives, e.g. a mono-oxime, semicarbazone, phenyland dinitrophenyl-hydrazone. It is readily oxidised by potassium mercuriiodide to the corresponding monobasic palitantic acid $\mathrm{C}_{14} \mathrm{H}_{22} \mathrm{O}_{5}$.

3. It does not contain a methoxyl group but contains two hydroxyl groups since it gives a dibromobenzoate.

4. It contains at least two double bonds since on catalytic reduction it gives tetrahydropalitantin, $\mathrm{C}_{14} \mathrm{H}_{26} \mathrm{O}_{4}$, which still contains the aldehyde group and is readily oxidised by hypoiodite to the corresponding monocarboxylic acid, tetrahydropalitantic acid $\mathrm{C}_{14} \mathrm{H}_{26} \mathrm{O}_{5}$.

5. The function of the fourth oxygen atom has not yet been determined. It does not appear to be present as a carbonyl group since neither a dioxime nor a di-phenylhydrazone (or osazone) could be obtained. Since palitantin only gives a dibromobenzoate it does not appear to contain more than two hydroxyl groups although it contains three active hydrogen atoms.

6. On reduction with sodium amalgam tetrahydropalitantin gives rise to a mixture of two isomeric hexahydro-derivatives, $\mathrm{C}_{14} \mathrm{H}_{28} \mathrm{O}_{4}$, each of which contains four active hydrogen atoms. Unlike their parent substance, neither of them gives a positive Schiff's reaction. They probably contain an alcohol grouping in place of the aldehyde group originally present.

7. Palitantin, $\mathrm{C}_{14} \mathrm{H}_{22} \mathrm{O}_{4}$, and tetrahydropalitantin, $\mathrm{C}_{14} \mathrm{H}_{26} \mathrm{O}_{4}$, are oxidised by $\mathrm{Ag}_{2} \mathrm{O}$ to dibasic acids $\mathrm{C}_{13} \mathrm{H}_{20} \mathrm{O}_{5}$ and $\mathrm{C}_{13} \mathrm{H}_{24} \mathrm{O}_{5}$ respectively, which were isolated as the dihydrazides.

Further work on the molecular structure of palitantin is in progress and will be reported at a later date.

\section{Experimental.}

\section{Cultures.}

The following strains of Penicillium palitans Westling were used:

(a) L.S.H.T.M. Cat. No. P. 126. Type strain purchased from Centraalbureau voor Schimmelcultures, Baarn, Holland, in August 1931. Received by them from Westling in 1929 and derived from his original strain. (b) L.S.H.T.M. Cat. No. P. 200, New Zealand strain No. 9. (c) L.S.H.T.M. Cat. No. P. 201, New Zealand strain No. 352. (d) L.S.H.T.M. Cat. No. P. 202, New Zealand strain No. 354.

Cultures $b, c$ and $d$ were received by us in January 1934 from Dr T. R. Vernon. They were sent to him in 1933 by Mr J. C. Neill of the Plant Research Station, Palmerston North, New Zealand, who diagnosed them as P. puberulum. They were isolated from discoloured New Zealand Cheddar cheese.

\section{Cultural conditions.}

The culture medium used throughout this work was a Raulin-Thom medium of the following composition: glucose, $75 \mathrm{~g}$.; tartaric acid, $4 \mathrm{~g}$.; diammonium tartrate, 4 g.; $\left(\mathrm{NH}_{4}\right)_{2} \mathrm{HPO}_{4}, 0.6$ g.; $\mathrm{K}_{2} \mathrm{CO}_{3}, 0.6$ g.; $\mathrm{MgCO}_{3}, 0.4$ g.; $\left(\mathrm{NH}_{4}\right)_{2} \mathrm{SO}_{4}$, $0.25 \mathrm{~g}$; $\mathrm{ZnSO}_{4}, 7 \mathrm{H}_{2} \mathrm{O}, 0.07 \mathrm{~g}$.; $\mathrm{FeSO}_{4}, 7 \mathrm{H}_{2} \mathrm{O}, 0.07 \mathrm{~g}$; d distilled water, $1500 \mathrm{ml}$. This was distributed in $350 \mathrm{ml}$. amounts in a number of 1-litre conical flasks, sterilised, sown with a spore suspension, prepared from Czapek-Dox glucose-agar 
slopes, of the organism studied and incubated at a chosen temperature until the glucose content, as determined by polarimeter, had fallen below $1 \%$. The yields of crude palitantin obtained per flask from P. 200, P. 201 and P. 202 were respectively $0 \cdot 10,0 \cdot 125$ and $0 \cdot 16 \mathrm{~g}$. at room temperature $\left(c a .18-20^{\circ}\right)$ and $0 \cdot 10$, $0 \cdot 10$ and $0 \cdot 02$ g. at $24^{\circ}$.

\section{Preparation of palitantin.}

Batches of 100 flasks of Raulin-Thom medium were sown with P.palitans, L.S.H.T.M. Cat. No. P. 202, New Zealand strain 354. (The strains P. 200 and P. 201 gave smaller yields of palitantin.) The flasks were incubated, originally at the temperature of the laboratory, but in all the later experiments in underground vaults, as the lower temperature prevailing there gave better yields of product. The most favourable temperature was found to be in the region of $10^{\circ}$. When the glucose content, as determined on a sample flask by polarimeter, was reduced to $0.4-0.9 \%$ (usually after $18-22$ days at $10^{\circ}$ ) the metabolism solution, which gave a positive Schiff's reaction, was filtered from the mycelium. Acidification before extraction was found to be unnecessary since palitantin is a neutral compound and undesirable since it gave rise to a product which did not readily crystallise. Extraction of the evaporated metabolism solution also resulted in a sticky product. Hence, in spite of its laborious nature, extraction of the unevaporated metabolism solution was followed as a routine procedure. The filtrate from each 20 flasks (about $6400 \mathrm{ml}$.) was extracted with chloroform. Two extractions were performed, each time using 2 litres of chloroform. The chloroform from the second extraction was used for the first extraction of a further batch of 20 flasks. The chloroform was removed under reduced pressure and the extracted material from the whole 100 flasks was combined. The crystals separating from the chloroform were filtered off and washed on the filter with ether, until a pure white product was obtained. A second and usually a third crop was obtained from the mother-liquor after dilution with ether. After complete evaporation of solvent an uncrystallisable syrup always remained, $5-6 \mathrm{~g}$. in weight.

The first crops of palitantin thus obtained were recrystallised from hot water ( 5 g. to 1 litre) and were then pure enough for most purposes. The second and third crops were twice recrystallised. The average yield at $10^{\circ}$ was $10-12 \mathrm{~g}$. per batch of 100 flasks. The experimental details of a number of preparations are given in Table I (batches 1-14).

\section{Isolation of palitantin using the type strain of $\mathrm{P}$. palitans Westling.}

One batch (Table I, batch No. 15) of 100 flasks was sown with the type strain of P. palitans, L.S.H.T.M. Cat. No. P. 126. The medium, cultural conditions and method of extraction were identical with those described in the previous sections. The $\mathrm{CHCl}_{3}$ extract $(12 \cdot 13 \mathrm{~g}$.) contained much uncrystallisable syrup as only $3.46 \mathrm{~g}$. of colourless crystalline material were isolated, M.P. $143^{\circ},[\alpha]_{5461}+27 \cdot 2^{\circ}$. This proved to be a mixture of palitantin with a dextrorotatory acid, which will form the subject of a future communication. The mixture was dissolved in $\mathrm{CHCl}_{3}(200 \mathrm{ml}$.), water $(50 \mathrm{ml}$.) was added and then, drop by drop, $N \mathrm{NaOH}$ $(4 \cdot 7 \mathrm{ml}$.) with vigorous shaking to neutrality to phenolphthalein. The aqueous phase was separated and acidified with HCl. An oil which quickly crystallised separated (1.01 g.) and is the dextrorotatory acid referred to above. The $\mathrm{CHCl}_{3}$ layer was treated with 4 vols. of light petroleum (B.P. 50-60 ${ }^{\circ}$ ). Palitantin, $1.45 \mathrm{~g}$., M.P. $157-9^{\circ}$, optically inactive, separated. Recrystallised from hot water in colourless needles, M.P. $165^{\circ}$, alone or mixed with sample from $P$. palitans, Cat. No. P. 202. 


\begin{tabular}{|c|c|c|c|c|c|c|c|c|c|}
\hline & & & $\begin{array}{l}\text { In. } \\
\text { cubation } \\
\text { period } \\
\text { in }\end{array}$ & Temperat & are $\left({ }^{\circ}\right)$ & $\begin{array}{c}\text { Residual } \\
\text { glucose } \\
\text { by } \\
\text { polari- } \\
\text { meter }\end{array}$ & $\begin{array}{l}\text { Final } \\
p_{\mathbf{H}} \text { of } \\
\text { meta- } \\
\text { bolism }\end{array}$ & $\begin{array}{c}\text { Titrat- } \\
\text { able } \\
\text { acidity } \\
\text { ml. } N / 10 \\
\mathrm{NaOH} \\
\text { per }\end{array}$ & $\begin{array}{l}\text { Yield of } \\
\text { crystalline } \\
\text { products }\end{array}$ \\
\hline & & & days & Range & Av. & $\%$ & solution & $10 \mathrm{ml}$ & g. \\
\hline 1. & Incubated & laboratory & 18 & - & - & $0 \cdot 78$ & $2 \cdot 9$ & $1 \cdot 42$ & $6 \cdot 12$ \\
\hline 2. & & , & 17 & Max. 27 & 20 & $0 \cdot 66$ & $3 \cdot 1$ & $1 \cdot 34$ & 3.42 \\
\hline 3. & Incubatec & vaults & 18 & $16-19$ & 18 & 0.73 & $3 \cdot 1$ & $1 \cdot 26$ & $11 \cdot 83$ \\
\hline 4. & , & , & 18 & - & - & 0.44 & $3 \cdot 3$ & $1 \cdot 20$ & $7 \cdot 67$ \\
\hline 5. & ," & , & 17 & $16 \cdot 5-21 \cdot 5$ & 19 & 0.56 & $3 \cdot 0$ & 1.52 & $8 \cdot 44$ \\
\hline 6. & $"$ & ", & 18 & $15-21$ & 18 & 0.44 & $3 \cdot 3$ & $1 \cdot 20$ & $9 \cdot 67$ \\
\hline 7. & ", & ", & 19 & $10-15$ & 13 & 0.56 & $2 \cdot 9$ & $1 \cdot 38$ & $13 \cdot 77$ \\
\hline 8. & " & ", & 19 & $6-15$ & 11 & $0 \cdot 83$ & $2 \cdot 9$ & $1 \cdot 67$ & $12 \cdot 67$ \\
\hline 9. & ", & ", & 22 & 6-13 & 8 & 0.64 & $3 \cdot 1$ & 1.45 & $11 \cdot 13$ \\
\hline 10. & , & , & 27 & $8-10$ & 9 & 0.42 & $3 \cdot 4$ & 0.79 & 13.96 \\
\hline 11. & ", & ", & 22 & $9-11$ & 10 & 0.66 & $2 \cdot 8$ & $1 \cdot 12$ & $12 \cdot 35$ \\
\hline 12. & ", & ", & 20 & $9-11$ & 10 & 0.85 & $2 \cdot 8$ & $1 \cdot 19$ & $9 \cdot 81$ \\
\hline 13. & , & ," & 20 & $10-12$ & 11 & 0.81 & $2 \cdot 9$ & $1 \cdot 32$ & $10 \cdot 49$ \\
\hline 14. & ," & , & 26 & $6-10$ & $8 \cdot 5$ & $0 \cdot 70$ & $3 \cdot 0$ & 1.02 & $11 \cdot 60$ \\
\hline 15. & ", & $"$ & 26 & $5-9$ & 7 & $0 \cdot 89$ & $2 \cdot 8$ & $6 \cdot 50$ & 3.46 \\
\hline
\end{tabular}

Palitantin crystallises from water in colourless needles. It may also be crystallised from alcohol, but with more loss. It is only slightly soluble in cold water and ether but is more readily soluble in hot water, alcohol or $\mathrm{CHCl}_{3}$. It is optically inactive and is neutral in reaction. It gives a positive Schiff's test and reduces $\mathrm{Ag}_{2} \mathrm{O}$ to metallic $\mathrm{Ag}$.

It behaves in a somewhat curious manner in a melting-point determination. At about $135^{\circ}$ a film of oily drops forms on the sides of the tube, the solid softens from about $150^{\circ}$ and is only completely melted at $163^{\circ}$. The colour is now yellowish. It resolidifies on cooling. This behaviour appears to be characteristic and not due to impurity since it was observed with every sample examined. Moreover, analytical figures agree well with a compound of definite composition, which is also borne out by analysis of derivatives. (Found (Schoeller), sample from P. 202 ex alcohol: C, 66.34; H, 8.81 \%. Sample from P. 202 ex water: C, 66.27; $\mathrm{H}, 8 \cdot 70 \%$. Sample from P. $126 \mathrm{ex}$ water : C, 66.12; H, 8.52\%. N, nil; $\mathrm{OCH}_{3}$, nil. Mol. wt. (Dr A. E. Oxford) cryoscopic in dioxan $256 . \mathrm{C}_{14} \mathrm{H}_{22} \mathrm{O}_{4}$ requires $\mathrm{C}, 66 \cdot 10$; H, $8.73 \%$. Mol. wt. 254.)

Palitantin contains three active hydrogen atoms since in a Zerewitinoff estimation it afforded 2.7 molecules of $\mathrm{CH}_{4}$ in anisole at $28^{\circ} ; 3 \cdot 1$ in anisole at $95^{\circ}$ and in pyridine.

\section{Derivatives of palitantin.}

Palitantin monosemicarbazone. Semicarbazide hydrochloride $(0 \cdot 11$ g.) dissolved in water $(2 \mathrm{ml}$.) was treated with $5 \%$ alcoholic potassium acetate $(2 \mathrm{ml}$.) followed by $0.11 \mathrm{~g}$. of palitantin. A clear solution resulted. After keeping overnight a good crop of crystals separated which were filtered off, washed with water and recrystallised from methyl alcohol. Yield $0.04 \mathrm{~g}$. of colourless needles, M.P. $212-213^{\circ}$ (decomp.). (Found (Schoeller): C, 58.26; H, 8.00; N, 13.69\%. $\mathrm{C}_{15} \mathrm{H}_{25} \mathrm{O}_{4} \mathrm{~N}_{3}$ requires $\mathrm{C}, 57 \cdot 84 ; \mathrm{H}, 8.10 ; \mathrm{N}, 13.49 \%$.) The substance is thus a monosemicarbazone of $\mathrm{C}_{14} \mathrm{H}_{22} \mathrm{O}_{4}$.

Palitantin monophenylhydrazone. Palitantin ( $0 \cdot 1 \mathrm{~g}$.) was heated with phenylhydrazine hydrochloride $(0.5 \mathrm{~g}$.$) , anhydrous sodium acetate (0.5 \mathrm{~g}$.$) and about$ $10 \mathrm{ml}$. of water in a boiling water-bath for half an hour. An orange-coloured 
insoluble substance was formed $(0 \cdot 13 \mathrm{~g}$.) which on recrystallisation from alcohol gave colourless needles, M.P. $175-176^{\circ}$, not raised by further recrystallisation. This product proved to be the monophenylhydrazone of palitantin. (Found (Weiler): C, 69.31; $\mathrm{H}, 8.15 ; \mathrm{N}, 8 \cdot 61 \%$. $\mathrm{C}_{20} \mathrm{H}_{28} \mathrm{O}_{3} \mathrm{~N}_{2}$ requires $\mathrm{C}, 69 \cdot 71 ; \mathrm{H}, 8.20$; $\mathrm{N}, 8 \cdot 14 \%$.) No evidence of a bisphenylhydrazone or osazone was obtained. The orange colour was due to a substance present only in small amount which could not be obtained in crystalline form.

Palitantin mono-oxime and mono-2:4-dinitrophenylhydrazone. Hydroxylamine hydrochloride $(0.14 \mathrm{~g}$.) was dissolved in water $(2 \mathrm{ml}$.) and $4 \mathrm{ml}$. of a $5 \%$ solution of potassium acetate in alcohol were added, followed by $0.25 \mathrm{~g}$. of palitantin. No crystals could be obtained so the mixture was evaporated to dryness in vacuo and the residue was extracted with ether. On evaporation of the ether an oily product remained which only crystallised after some months. It could not be recrystallised, and melted at 104-106 ${ }^{\circ}$. It is doubtless the oxime of palitantin. As it was readily soluble in water it was used without further purification to investigate the point as to whether there is a second ketonic or aldehydic group in palitantin. Its aqueous solution was treated with an excess of 2:4-dinitrophenylhydrazine in $2 \mathrm{~N} \mathrm{HCl}$ in the hope of obtaining a mixed oxime2:4-dinitrophenylhydrazone. A yellow precipitate was obtained which was recrystallised twice from methyl alcohol; yellow needles, M.P. 209 ${ }^{\circ}$ (Found (Schoeller): C, 54.87; H, 6.10; N, 13.35\% C $_{20} \mathrm{H}_{26} \mathrm{O}_{7} \mathrm{~N}_{4}$ requires $\mathrm{C}, 55 \cdot 27 ; \mathrm{H}, 6 \cdot 04$; $\mathrm{N}, 12.90 \%$.) Hence the oxime group has been eliminated and replaced by a dinitrophenylhydrazine group, the product being palitantin 2:4-dinitrophenylhydrazone. There is thus no evidence for another ketonic or aldehydic group in palitantin.

Palitantin di-p-bromobenzoate. Palitantin (0.25 g.) was heated with $p$-bromobenzoyl chloride $(0.7 \mathrm{~g}$.) in pyridine $(5 \mathrm{ml}$.) on the water-bath until the mixture began to darken in colour (10 minutes). After cooling, water $(40 \mathrm{ml}$.) was added and the brownish oil which precipitated was separated from the aqueous portion and shaken with a few ml. of sodium bicarbonate solution. After keeping overnight the oil was taken up in a little warm alcohol and water was added until a slight turbidity appeared. The crystals which separated were recrystallised three times in the same manner from aqueous alcohol; colourless plates, M.P. 153-154 ${ }^{\circ}$. (Found (Schoeller): C, 54.24, 54.33; H, 4.72, 4.66; Br, 26.45\% $\mathrm{C}_{28} \mathrm{H}_{28} \mathrm{O}_{6} \mathrm{Br}_{2}$ requires $\mathrm{C}, 54 \cdot 18 ; \mathrm{H}, 4.55 ; \mathrm{Br}, 25 \cdot 77 \%$.)

Palitantic acid, $\mathrm{C}_{14} \mathrm{H}_{22} \mathrm{O}_{5}$. Doeuvre's reagent [1927] was found to oxidise the aldehyde group in palitantin to a carboxyl group almost quantitatively. Palitantin (2.54 g. from P. 202) suspended in water (1 litre) was treated with a solution of $\mathrm{HgI}_{2}(4.54 \mathrm{~g}$.) and $\mathrm{KI}(30 \mathrm{~g}$.) in water $(25 \mathrm{ml}$.). After adding $50 \mathrm{ml}$. $N \mathrm{NaOH}$ the mixture was left for some hours with occasional shaking. The solution was filtered through kieselguhr to remove mercury and titrated. It required $20.5 \mathrm{ml} . N \mathrm{HCl}$, showing a production of $29.5 \mathrm{ml}$. of $N$ acid in the reaction, the theoretical amount being $30.0 \mathrm{ml}$. $10 \mathrm{ml}$. of $2 N \mathrm{HCl}$ were then added. Palitantic acid began to crystallise immediately. After chilling, the product was collected; long colourless needles, M.P. 146-148 ${ }^{\circ}$, wt. 1.63 g., which did not require further recrystallisation.

Palitantin from P. 126 behaved in an exactly similar manner with Doeuvre's reagent, giving palitantic acid, M.P. $145-147^{\circ}$, alone or mixed with palitantic acid from P. 202. (Found (Weiler), sample ex P. 202: C, 62.06, 62.28; H, 8.11, $8.04 \%$. Sample ex P. 126: C, 62.07; H, 8.25\%. Equiv. by titration, 270.5. $\mathrm{C}_{14} \mathrm{H}_{22} \mathrm{O}_{5}$ requires $\mathrm{C}, 62 \cdot 18 ; \mathrm{H}, 8 \cdot 21 \%$. Equiv. titrating as a monobasic acid, 270.) 
Tetrahydropalitantin, $\mathrm{C}_{14} \mathrm{H}_{26} \mathrm{O}_{4}$. Palitantin ( $\mathrm{lg}$.) dissolved in alcohol (100 ml.) was hydrogenated using a Pd-norite catalyst. The absorption of hydrogen was rapid and ceased after $5 \mathrm{~min}$., when the equivalent of 2 mols. of $\mathrm{H}_{2}$ had been absorbed. The solution still gave Schiff's test. After filtration the solution was evaporated to small volume and about 4 vols. of water were added. The product separated in the form of colourless needles, M.P. $115^{\circ}$, and was filtered off. A further crop was obtained on concentration of the filtrate. The yield was quantitative. The product was recrystallised from alcohol and water (1:5). A sample sublimed in a high vacuum melted at $116^{\circ}$. It solidified on cooling and re-melted at the same temperature. (Found (Schoeller): C, 65.17, 65.20; H, 10.21, 10.29\%. $\mathrm{C}_{14} \mathrm{H}_{26} \mathrm{O}_{4}$ requires $\mathrm{C}, 65 \cdot 07 ; \mathrm{H}, 10 \cdot 15 \%$. Zerewitinoff estimation (Roth): Tetrahydropalitantin affords 3.3 mols. of $\mathrm{CH}_{4}$ in anisole at $18^{\circ}, 3.0$ in pyridine at $18^{\circ}$.)

Monosemicarbazone of tetrahydropalitantin. Details as for the semicarbazone of palitantin (p. 804). After keeping overnight no crystals had appeared, so water was cautiously added until crystallisation began. The product was recrystallised from a mixture of methyl alcohol and water; colourless rosettes of needles, M.P. $188-189^{\circ}$ after softening at $186^{\circ}$. There was some darkening at the M.P. (Found (Schoeller): C, 57.22; H, 9.37; N, 13.01\% . $_{15} \mathrm{H}_{29} \mathrm{O}_{4} \mathrm{~N}_{3}$ requires C, 57.10; $\mathrm{H}, 9 \cdot 27 ; \mathrm{N}, 13 \cdot 32 \%$.)

$\alpha$-Hexahydropalitantin and $\beta$-hexahydropalitantin. Tetrahydropalitantin $(0.5 \mathrm{~g}$.) was dissolved in alcohol $(50 \mathrm{ml}$.$) and 2.5 \%$ sodium amalgam $(100 \mathrm{~g}$.$) and$ $\mathrm{N} \mathrm{H}_{2} \mathrm{SO}_{4}(110 \mathrm{ml}$.) were added each in ten lots over a period of about 4 hours. The mixture was thus never allowed to become alkaline, since the amount of acid was slightly in excess of that required to neutralise the sodium hydroxide produced. The mixture was heated on the water-bath under reflux. The solution was then extracted with chloroform and the solvent evaporated in vacuo. The residue was extracted with boiling ether (about $250 \mathrm{ml}$.) for some time but a small amount failed to dissolve and was filtered off; wt. 0.04 g., M.P. 140-142 ${ }^{\circ}$. When recrystallised from water it separated in the form of colourless plates, M.P. $142-143^{\circ}$. On chilling the ether filtrate, a further amount $(0.08$ g.) of the material, M.P. $135-136^{\circ}$, was obtained. It gave the same product, M.P. 142-143 ${ }^{\circ}$, on recrystallisation. It contains 2 atoms of hydrogen more than the original substance, and unlike the latter it gives no Schiff's reaction. It was termed $\alpha$-hexahydropalitantin. (Found (Weiler): C, 64.39; $\mathrm{H}, 10 \cdot 87 \% . \mathrm{C}_{14} \mathrm{H}_{28} \mathrm{O}_{4}$ requires $\mathrm{C}, 64.57 ; \mathrm{H}, 10.84 \%$.) In a Zerewitinoff estimation (Roth) it gave 3.91 , 3.93 mols. of $\mathrm{CH}_{4}$ in pyridine, and $3 \cdot 34,3.84$ mols. in anisole, at $18^{\circ}$ and $95^{\circ}$ in each case respectively.

The ether mother-liquor when evaporated to about $10-15 \mathrm{ml}$. gave $0 \cdot 10 \mathrm{~g}$. of crystals (plates), M.P. $90-93^{\circ}$. On recrystallisation from water, then from ether, the M.P. was raised to $98-99^{\circ}$. There was a syrupy residue from the ether of $0 \cdot 23 \mathrm{~g}$. The substance, M.P. $98-99^{\circ}$, proved to be isomeric with $\alpha$-hexahydropalitantin and like that substance it gave no Schiff's reaction. It was termed $\beta$-hexahydropalitantin. (Found (Schoeller): C, 64.43; H, 10.72\% . $\mathrm{C}_{14} \mathrm{H}_{28} \mathrm{O}_{4}$ requires $\mathrm{C}, 64.57 ; \mathrm{H}, 10.84 \%$.) In a Zerewitinoff estimation (Roth) it gave 3.83 , 3.85 mols. of $\mathrm{CH}_{4}$ in pyridine, and $3.73,3.81$ mols. in anisole, at $18^{\circ}$ and $95^{\circ}$ in each case respectively.

Reaction of tetrahydropalitantin with hypoiodite. Tetrahydropalitantin $(0.0403$ g.) was dissolved in $100 \mathrm{ml}$. of water by warming. The solution was cooled and to it were added $40 \mathrm{ml}$. of $N / 10$ iodine from a pipette and approximately $50 \mathrm{ml}$. of $\mathrm{N} / 10 \mathrm{NaOH}$. After keeping overnight $5 \mathrm{ml}$. of $2 \mathrm{~N}_{2} \mathrm{SO}_{4}$ were added and the unused iodine was titrated. A blank experiment was performed on the reagents. The iodine absorbed, $3.07 \mathrm{ml}$. of $N / 10$, corresponded with 
1.97 atoms of iodine per mol. of tetrahydropalitantin. The most probable reaction would be an oxidation of an aldehyde group to a carboxyl group and a larger-scale experiment showed that this actually occurs.

Tetrahydropalitantic acid. Tetrahydropalitantin $(0 \cdot 4 \mathrm{~g}$.) was dissolved in 1 litre of water by warming, and to the cooled solution $200 \mathrm{ml}$. of $N / 10$ iodine and $250 \mathrm{ml}$. of $\mathrm{N} / 10 \mathrm{NaOH}$ were added, the latter slowly and with shaking. After keeping overnight $25 \mathrm{ml}$. of $2 \mathrm{~N} \mathrm{H}_{2} \mathrm{SO}_{4}$ were added and the solution was titrated with thiosulphate. The iodine used, $2.15 \mathrm{ml}$. $N$, corresponded with only $69 \%$ conversion of aldehyde into acid. The only difference between this experiment and the previous one, except in scale, was a reduction in the excess of alkaline iodine employed. Evidently about 14 times the theoretical amount is required for complete conversion.

The solution was extracted with ether, using about $400 \mathrm{ml}$. in two lots; the acids were transferred to sodium carbonate solution which was acidified and extracted with ether. The yield of acids, $0 \cdot 25 \mathrm{~g}$., represents $59 \%$ of the theoretical amount. The product set to a mass of crystals. It was recrystallised from ether giving colourless plates, M.P. $110^{\circ}$, to an opaque liquid clearing at $135^{\circ}$. (Found (Schoeller): C, 61.18, 61.12; H, 9.56, 9.48\%. Equiv. by titration 275 . $\mathrm{C}_{14} \mathrm{H}_{26} \mathrm{O}_{5}$ requires $\mathrm{C}, 61 \cdot 27 ; \mathrm{H}, 9 \cdot 56 \%$. Equiv. (titrating as a monobasic acid) 274.) In a Zerewitinoff estimation (Roth) it gave 3.77, 3.92 mols. of $\mathrm{CH}_{4}$ in pyridine and $1.90,1.86$ mols. in anisole, at $18^{\circ}$ and $95^{\circ}$ in each case respectively.

Oxidation of palitantin, $\mathrm{C}_{14} \mathrm{H}_{22} \mathrm{O}_{4}$, to a dicarboxylic acid, $\mathrm{C}_{13} \mathrm{H}_{20} \mathrm{O}_{5}$. Palitantin (1 g.) and silver oxide (5 g.) were mixed in about $150 \mathrm{ml}$. of water and the mixture was heated in boiling water under reflux for 1 hour. There was reduction of the silver oxide and formation of a silver mirror. The mixture was acidified with $7 \mathrm{ml}$. of concentrated $\mathrm{HCl}$ and extracted with ether. The acids were extracted from the ether by means of aqueous $\mathrm{NaHCO}_{3}$ and then transferred to ether after acidification. On evaporation of the ether, $0.4 \mathrm{~g}$. of a yellow oily residue remained, smelling somewhat of butyric acid. This was esterified with diazomethane in ether and after removal of the ether and excess diazomethane was treated with $1 \mathrm{ml}$. of alcohol and $1 \mathrm{ml}$. of $50 \%$ aqueous hydrazine hydrate. In a few minutes crystals appeared, and the mass became semi-solid. The crystals after separation and washing with alcohol and ether melted at 201-202 ${ }^{\circ}$, after shrinking at $198^{\circ}$, and weighed 0.08 g. The M.P. was unchanged after recrystallisation from alcohol. Analysis showed that this substance was the dihydrazide of a dicarboxylic acid $\mathrm{C}_{13} \mathrm{H}_{20} \mathrm{O}_{5}$ (or its lactone $\mathrm{C}_{13} \mathrm{H}_{18} \mathrm{O}_{4}$ ). (Found (Schoeller): $\mathrm{C}, 54 \cdot 75 ; \mathrm{H}, 8 \cdot 50 ; \mathrm{N}, 19 \cdot 67 \%$. $\mathrm{C}_{13} \mathrm{H}_{24} \mathrm{O}_{3} \mathrm{~N}_{4}$ requires $\mathrm{C}, 54 \cdot 89 ; \mathrm{H}, 8 \cdot 51 ; \mathrm{N}, 19 \cdot 72 \%$.)

Oxidation of tetrahydropalitantin, $\mathrm{C}_{14} \mathrm{H}_{26} \mathrm{O}_{4}$, to a dicarboxylic acid, $\mathrm{C}_{13} \mathrm{H}_{24} \mathrm{O}_{5}$. Details as for the oxidation of palitantin. The syrupy acids weighed $0.49 \mathrm{~g}$. The esters became solid almost immediately on addition of $1 \mathrm{ml}$. of alcohol and $1 \mathrm{ml}$. of hydrazine hydrate $(50 \%)$. The crude product $(0 \cdot 19 \mathrm{~g}$.) after recrystallisation from alcohol yielded $0.13 \mathrm{~g}$. of material melting at $190^{\circ}$ after softening at $188^{\circ}$. Analysis showed that it was the dihydrazide of a dicarboxylic acid $\mathrm{C}_{13} \mathrm{H}_{24} \mathrm{O}_{5}$ (or its lactone $\mathrm{C}_{13} \mathrm{H}_{22} \mathrm{O}_{4}$ ). (Found (Schoeller): C, 54.23; H, 9.74; N, $19 \cdot 49 \%$. $\mathrm{C}_{13} \mathrm{H}_{28} \mathrm{O}_{3} \mathrm{~N}_{4}$ requires $\mathrm{C}, 54 \cdot 12 ; \mathrm{H}, 9 \cdot 79 ; \mathrm{N}, 19 \cdot 44 \%$.) In an attempt to improve the yield of this product the conditions of the experiment were varied and other oxidising agents, e.g. bromine, $\mathrm{CrO}_{3}$ in acetic acid and nitric acid, were tried. Bromine did not appear to give rise to acidic products under the conditions employed, and $\mathrm{CrO}_{3}$ and nitric acid (the latter diluted with water in the proportion 1 in 3) gave rise to the same product as silver oxide in yields of the same order. 


\section{SUMMARY.}

Palitantin, $\mathrm{C}_{14} \mathrm{H}_{22} \mathrm{O}_{4}$, a hitherto undescribed mould metabolic product, is formed on Raulin-Thom medium by the type strain of Penicillium palitans Westling, and by three different strains of the same species isolated from certain discolorations in New Zealand Cheddar cheese. Various derivatives and reduction and oxidation products of palitantin are described. Palitantin is an unsaturated dihydroxyaldehyde of, at present, unsettled molecular constitution.

We desire to thank Mr.W. K. Anslow for much technical assistance in the preparation of quantities of palitantin. We tender our best thanks to the Research Council of Imperial Chemical Industries, Ltd., for a grant to one of us (J. H. B.).

\section{REFERENCES.}

Alsberg and Black (1913). U.S. Dept. Agric. Bureau Plant Ind. Bull. No. 270. Birkinshaw, Oxford and Raistrick (1936). Biochem. J. 30, 394.

Doeuvre (1927). Bull. Soc. Chim. (iv), 41, 1145.

Moir (1933). J. Dairy Res. 4, 238.

Morgan (1933). J. Dairy Res. 4, 226.

Westling (1911). Arkiv Botanik, 2, 83-86. 